\title{
Cultura Cultura
}

Revista de Historia Teorid das ldeaias - Revista de História e Teoria das Ideias

Vol. 25 | 2008

Varia

\section{Os Estados Unidos da América nas Memórias do Conde do Lavradio}

The United States in Count Lavradio's Memories

Júlio Joaquim da Costa Rodrigues da Silva

\section{(2) OpenEdition}

Journals

Edição electrónica

URL: http://journals.openedition.org/cultura/576

DOI: $10.4000 /$ cultura.576

ISSN: 2183-2021

Editora

Centro de História da Cultura

Edição impressa

Data de publição: 1 Junho 2008

Paginação: 11-30

ISSN: 0870-4546

\section{Refêrencia eletrónica}

Júlio Joaquim da Costa Rodrigues da Silva, « Os Estados Unidos da América nas Memórias do Conde

do Lavradio », Cultura [Online], Vol. 25 | 2008, posto online no dia 01 outubro 2013, consultado a 21

abril 2019. URL : http://journals.openedition.org/cultura/576 ; DOI : 10.4000/cultura.576 


\title{
Os Estados Unidos da América nas Memórias do Conde do Lavradio
}

\author{
Júlio Joaquim da Costa Rodrigues da Silva*
}

O ano de 2008 caracteriza-se, na cena internacional, por diversos acontecimentos que modificam gradualmente a imagem do mundo em que vivemos. A ascensão de novas potências como a União Indiana e a República Popular da China, a aceleração do processo de unificação europeia, as recorrentes dificuldades no Médio Oriente, o terrorismo fundamentalista e a ameaça de uma crise financeira são elementos fulcrais da presente paisagem política. O horizonte político global não pode ser plenamente apreendido sem considerarmos a evolução da única superpotência existente: os EUA! Ora, 2008 é assinalado com especial relevância pelas eleições presidenciais americanas. Está em jogo a definição das orientações da política externa do país que tem um peso fundamental no equilíbrio universal. O facto de as escolhas internas dos candidatos dos EUA mobilizarem o interesse dos meios de comunicação e da opinião pública demonstra até que ponto os Estados Unidos da América estão no centro das nossas representações culturais e políticas.

\section{0 regresso ao reino}

A influência destes modelos na visão europeia do mundo é antiga, podendo ser detectada, desde a sua fundação, em inúmeros observadores, entre os quais se inclui D. Francisco d'Assis de Almeida Portugal (1796-1870), 2. ${ }^{\circ}$ conde do Lavradio. As Memórias, de sua autoria, são um testemunho dos mais interessantes da história do século XIX. Foi uma das personalidades mais importantes da implantação do liberalismo em Portugal, tendo desempenhado um papel primacial como ministro, parlamentar e diplomata. Nasceu em Lisboa em 1796 numa das famílias de maior prestígio da aristocracia, tendo acompanhado os pais quando a Corte partiu para o Brasil em 1807, durante a primeira invasão francesa de Junot. Residiu no Rio de Janeiro de 1808 até 1818, regressando então a Lisboa para iniciar a sua carreira diplomática no cargo de conselheiro de embaixada em Madrid. A descrição da partida do Brasil e da chegada a Lisboa, nesse mesmo ano, dá-nos uma ideia da sua dupla pertença ao Brasil e a Portugal e define bem a sua identidade luso-brasileira:

\footnotetext{
* Centro de História da Cultura.
} 
"Foi por Decreto de 2 de Janeiro de 1818 que fui nomeado Conselheiro de Embaixada na Côrte de Madrid, sendo em 6 de Fevereiro nomeado Commendador da nova Ordem da Conceição.

No dia 20 de Maio, quarta-feira, pouco depois da meia noite, embarquei na praia da Nossa Senhora da Gloria, para bordo da nau S. Sebastião, acompanhando-me até lá o meu bom e respeitavel mestre e amigo, Padre João Baptista, o Coronel João Pedro Lecor, Caetano Pitta, e varios creados e escravos de meu Pae. Não descreverei a despedida de meus Paes e irmãos; todos calcularão quanto me custou a separação que sómente era atenuada pelo empenho que eu tinha de conhecer o mundo e me instruir; mal pensava eu então que o beijo que dava a minha Mãe era bem um beijo de despedida e que não mais a tornaria a ver!

De manhã começámos a levantar ferro, mas o vento não deu logar a sahirmos e, conseguintemente, voltei a terra em companhia de Diogo V. F.; ás onze da noite voltei para bordo com o dito Diogo, soffrendo durante o caminho grande trabalho por causa da agitação em que o mar se achava. No dia 21 tambem nos faltou vento para podermos sahir, mas não me foi possivel ir a terra por causa do estado de molestia em que me achava. A 22, ás nove e meia da manhã, sahimos do Rio de Janeiro, morrendo um homem despedaçado por cahir duma verga sobre uma lancha; a 6 de Junho cahiram dois homens ao mar, que não se poderam salvar; a 8, ás dez da manhã, passámos a linha; a 9, ás onze da noite, vi a estrella do norte; a 11 fallámos com um navio inglez que vinha do Rio de Janeiro com vinte e nove dias de viagem, e a 30 de Julho entrámos a barra de Lisboa, tendo avistado na viagem as ilhas do Côrvo, Flôres e Ferro.

Cheguei a terra ás quatro horas d'esse dia, depois de nove annos de ausencia. Não me é possivel descrever a alegria que senti ao ver a minha irmã Eugenia, a commoção ao entrar na casa em que nascera, as interminaveis conversas sobre os acontecimentos d'estes longos nove annos, emfim as innumeras perguntas que todos me dirigiam. Em Lisboa me demorei todo o resto d'este anno, e só a 19 de Abril do seguinte parti para o meu posto de Madrid, onde cheguei a 1 de Maio, pela tarde."1

O aspecto emotivo da partida do Brasil separando-se a custo da sua família restrita e extensa, que incluía clientes, criados e escravos, é característico de uma linhagem aristocrática; atesta a importância do Brasil na construção da sua personalidade, através dos afectos a que estão ligadas as suas recordações de infância. A chegada a Lisboa demonstra igualmente a sua ligação à velha pátria metropolitana, representada aqui pelo amor fraternal da irmã Eugénia e, portanto, uma identidade partilhada entre as duas margens atlânticas do Reino Unido de Portugal e Brasil (1816). O Brasil marcara-o pela formação que

Cf.Portugal, Francisco de Almeida, Memórias do Conde do Lavradio..., Coimbra, Imprensa da Universidade, 1932, Vol. I, p. 63. 
obtivera, graças ao ensino ministrado por Silvestre Pinheiro Ferreira (1769-1846) - publicista liberal e mais tarde diplomata e ministro do vintismo - que lhe permitiu completar a preparação académica que começara em Portugal ${ }^{2}$. O Brasil, transformado em sede da monarquia portuguesa, ganhara entretanto a coesão e as instituições políticas de um Estado moderno, abandonando, na prática, o estatuto de colónia do reino de Portugal. Foi esta a realidade que não deixou de marcar o conde do Lavradio na sua juventude e que, provavelmente, transportou consigo quando regressou ao reino em 1818.

A sua carreira diplomática levou-o, nos anos que se seguiram, a Madrid e a Paris, onde teve contacto com o universo da política e da cultura europeias. A Revolução liberal de 1820 não o afectou senão marginalmente. A extinção do lugar de conselheiro de embaixada em Paris foi imediatamente compensada pela nomeação para encarregado de negócios em Viena de Áustria, pelo seu antigo professor e amigo Silvestre Pinheiro Ferreira, ministro dos Negócios Estrangeiros do novo governo liberal. A ruptura das relações diplomáticas com Viena de Áustria impediu a ocupação deste cargo; só em Abril de 1824 é nomeado secretário da embaixada de Paris e nesse mesmo ano, Ministro residente nos Estados Unidos, lugar que por razões desconhecidas nunca ocupou. Regressando a Lisboa em Novembro, é então apresentado a D. João IV! Em todo este percurso a marca americana está sempre presente, embora os Estados Unidos pareçam paradoxalmente distantes, a não ser por esta nomeação sem seguimento ${ }^{3}$. A nomeação do conde do Lavradio em 1 de Agosto de 1826 para ministro dos Negócios Estrangeiros, sob a égide da Carta Constitucional de 1826, doada por D. Pedro IV, não alterou esta realidade. O governo da regente, D. Isabel, estava demasiado preocupado com os problemas relacionados com a sobrevivência do regime constitucional, perante as conspirações e revoltas miguelistas

2 "Pouco sei do autor das Memorias, de 1808 a 1818. Tendo apenas doze annos, quando chegou ao Brasil, e vinte e dois, quando d'alli sahiu, é natural que esses annos fôssem passados em estudos. Ignoro quaes fôssem os seus mestres, sabendo apenas que um d'elles foi Silvestre Pinheiro Ferreira, que naturalmente lhe incutiu as ideas liberaes que professava e que, como atraz vimos, annos antes fôra obrigado a expatriar-se. Outro dos seus mestres foi Fr. Leandro do Sacramento, botanico de merito, bacharel licenciado pela Universidade de Coimbra e Professor Regio de Agricultura e Botanica na cidade do Rio de Janeiro. Quando em 1814 foi creada a cadeira de Agricultura e Botanica, foi D. Francisco de Almeida um dos primeiros alumnos d'essa Cadeira e fez exame com applauso em 6 de Dezembro de 1815.", Sá, João de Almeida Correia de, Portugal, Francisco de Almeida, Memórias do Conde do Lavradio..., Coimbra, Imprensa da Universidade, 1932, Vol. I, p. 21. Sobre Silvestre Pinheiro Ferreira consultar Pereira, José Esteves, Silvestre Pinheiro Ferreira, o seu Pensamento Político, Coimbra, Universidade de Coimbra, 1974, pp. 1-27.

3 Cf. Sá, João de Almeida Correia de, Portugal, Francisco de Almeida, Memórias do Conde do Lavradio..., Coimbra, Imprensa da Universidade, 1932, Vol. I pp. 76-79. 
e as ameaças de invasão espanhola do exército de D. Fernando VII. Assim sendo, a preocupação essencial de D. Francisco de Almeida era ancorar o regime da Carta de 1826 e a independência nacional na "intima união com a Inglaterra". A opção não se devia a qualquer parti pris, ou ilusão, quanto à Grã-Bretanha mas a uma análise, que se desejava objectiva, dos interesses das diversas potências face a Portugal ${ }^{4}$.

Nesta perspectiva, os seus esforços, nos dois governos de 1826-1827 nos quais desempenha as funções de ministro dos Negócios Estrangeiros, têm êxito na obtenção do apoio britânico que envia a Portugal a divisão Clinton, a 12 de Outubro de 1827. Com o auxílio do embaixador inglês em Portugal e do governo britânico, trava uma ameaça de invasão espanhola e consegue obter o apoio político para que a divisão liberal do exército do conde de Vila Flor derrote os revoltosos legitimistas. O governo constitucional fica reforçado e obtém-se um período de paz entre todos os partidos e o funcionamento regular das instituições da Carta de 1826, onde será deputado eleito pela Beira em 1826-1827. A prioridade dada a esta estratégia diplomática implicava uma desvalorização de outras áreas e, entre elas, como o próprio confessa, o aspecto totalmente secundário das relações com os Estados Unidos da América, apenas representados em Portugal pelo encarregado de negócios, Brent ${ }^{5}$. O regresso de D. Miguel a Lisboa em 1828 acaba por levar a um evolução política do país que lhe é nefasta com o triunfo dos legitimistas, a queda da Carta e o retorno do absolutismo. Na sequência destes acontecimentos, para iludir a prisão, emigra para Londres e refugia-se com o pai na Bélgica. O período de exílio inicia-se aqui e continua ao longo dos anos seguintes até ao final da Guerra Civil em 1834. Em nome da Regência

4 "Quem ler com attenção a minha correspondencia, descobrirá nella que a base do meu systema politico era a intima união com a Inglaterra. Qual é a potencia continental que hoje tem interesse na conservação de Portugal? Será a França? Certamente, não, pois esta potencia acharia uma excellente indemnização de engrandecimento de Hespanha, se estendesse o seu dominio até ás margens do Ebro, por exemplo. As outras grandes potencias europêas é perfeitamente indifferente, segundo o systema actual, que Portugal exista ou deixe de existir.

É, portanto, a Gran-Bretanha a única potencia que pode ter interesse na conservação de Portugal, não por causa dos interesses commerciaes, os quaes hoje são muito diminutos, mas pelos interesses politicos. Portugal é uma das portas principaes que a Gran-Bretanha tem no continente, por ella introduz a Inglaterra na Europa o que julga conveniente, bem como embaraça o que lhe podér ser nocivo. A consideração, pois, de que a Inglaterra é a única potencia que tem um interesse directo e real na conservação prospera de Portugal decidiu-me a ligar-me francamente com aquella potencia, e parece-me que ninguem ousará desmentir-me, se eu disser que Portugal deve a conservação ou a salvação das suas liberdades e, por isso, da sua felicidade á Inglaterra.", Portugal, Francisco de Almeida, Memórias do Conde do Lavradio..., Coimbra, Imprensa da Universidade, 1932, Vol. I, p. 108.

5 "De Mr. Dal Borgo, Massimino, Kantzow, e Brent é escusado fallar pela nenhuma importancia politica.", Portugal, Francisco de Almeida, Memórias do Conde do Lavradio..., Coimbra, Imprensa da Universidade, 1932, Vol. I, p. 114. 
liberal dos Açores, em 26 de Abril de 1830 desempenha as funções de enviado extraordinário e ministro plenipotenciário em Paris. As referências aos Estados Unidos da América são praticamente inexistentes nestes anos nas suas Memórias, pois o reconhecimento de facto do governo miguelista por aquele país é um acontecimento menor ${ }^{6}$.

No período seguinte que decorre entre 1831 e 1833 e, portanto, cobre quase toda a época da Guerra Civil (1828-1834), as referências aos Estados Unidos da América são igualmente escassas e esparsas. Os problemas mais graves de momento estão ligados ao regresso de D. Pedro IV do Brasil e à luta contra D. Miguel. Assim sendo, compreende-se que uma primeira alusão indique apenas o nome do enviado extraordinário dos Estados Unidos da América do Norte, Mr. Rives, a propósito do envio do manifesto do Imperador aos governantes franceses e aos membros do Corpo Diplomático presente em Paris, em Fevereiro de 1832. O Manifesto de D. Pedro, Duque de Bragança (02/02/1832) declarava a intenção de defesa dos direitos da sua filha, D. Maria da Glória, ao trono de Portugal, contestando a usurpação de D. Miguel!

A partida da expedição liberal de D. Pedro IV dos Açores e o desembarque e entrada no Porto (1832) suscitaram naturais temores entre as autoridades miguelistas em Lisboa. $\mathrm{O}$ receio de um desembarque constitucional na Capital era reforçado pela presença de uma esquadra da Royal Navy, depois da anterior destruição da marinha de guerra portuguesa levada a cabo por uma frota francesa (1831). A chegada de navios de guerra americanos a 4 de Junho de 1832 deu origem a uma série de boatos favoráveis ao governo absolutista; não desmentidos, de imediato, pelo encarregado de negócios dos EUA que tinha conhecimento do motivo: o pagamento de indemnizações aos navios mercantes daquele país pelos danos causados pelo bloqueio da ilha Terceira ${ }^{8}$.

Os meses que se seguem deste ano de 1832 e do seguinte são marcados pelos violentos combates do Cerco do Porto, no qual o pequeno exército liberal luta pela sobre-

6 A única referência vem aliás de uma carta do francês Lefèvre, correspondente em Lisboa do Conde do Lavradio, e apenas referente a uma ameaça de ataque naval da esquadra americana se não for dada aos EUA uma indemnização por danos causados aos navios mercantes daquele país no bloqueio naval da esquadra miguelista à ilha Terceira na posse dos liberais: "(...) On dit qu'on va armer tout le monde, mais il n'y a ni fusils ni bonne volonté ... On fabrique des chuços à force á l'Arsenal. Comme il n'es question que de nous et de l'escadre des Etats-Unis qui doit venir demander 500000 piastres de dommages-intérêts, je ne saurai vous en dire davantage.", Portugal, Francisco de Almeida, Memórias do Conde do Lavradio..., Coimbra, Imprensa da Universidade, 1932, Vol. I, p. 383.

7 Cf.Portugal, Francisco de Almeida, Memórias do Conde do Lavradio..., Coimbra, Imprensa da Universidade, 1932, Vol. Il, p. 171.

8 Cf.Portugal, Francisco de Almeida, Memórias do Conde do Lavradio..., Coimbra, Imprensa da Universidade, 1932, Vol. II, p. 242. 
vivência perante o sítio de um exército absolutista muito superior em número e meios. Neste contexto a chegada contínua de reforços em tropas, armas, munições, mantimentos e dinheiro era fundamental para garantir a resistência da capital do Norte e a causa de D. Maria II. Os esforços diplomáticos dos constitucionais redobram na Europa, sobretudo na Grã-Bretanha e na França, tentando obter o reconhecimento do governo de D. Pedro e recursos para a continuação da resistência armada contra os miguelistas. Entretanto, as tentativas dos diplomatas de D. Miguel vão no sentido de conseguirem, da parte da Inglaterra e da França, a aceitação da legitimidade do seu governo em Lisboa. As preocupações de D. Francisco de Almeida atingem o clímax em Fevereiro de 1833 quando se apercebe da disponibilidade do ministério francês do duque de Broglie de reconhecer oficialmente o governo miguelista. O momento era crítico para as forças liberais no Porto e, portanto, os governantes gauleses mostravam-se disponíveis para o fazer. Apontavam como exemplo o que tinha sido feito pelos Estados Unidos da América - uma república que, implicitamente, era um regime político muito mais radical do que uma monarquia constitucional e, em teoria, impossível de acreditar que transigisse com o absolutismo?.

O fim da Guerra Civil, em 1834, traduziu-se numa progressiva institucionalização do regime liberal, inicialmente sob a égide da Carta Constitucional de 1826 . O período que decorreu entre 26 de Maio de 1835 e Abril de 1836 passou-o ocupando-se na Inglaterra, França e Alemanha em obter um príncipe para a rainha, recaindo a escolha final em D. Fernando de Saxe-Cobourg. Opõe-se à Revolução de 9 de Setembro de 1836 com os outros pares do reino e mantém-se afastado da actividade política e diplomática, de novo, devido a ter-se recusado a jurar a Constituição de 1838. O golpe de estado de Costa Cabral, em Janeiro de 1842, que restaurou a Carta de 1826, transforma-o, na Câmara dos Pares, num dos grandes adversários do cabralismo até à sua queda final em 1851. D. Francisco de Almeida foi um dos suportes da nova situação, mas recusou participar em qualquer governo. Afirmando-se como "o homem da legalidade", não estava talhado para tomar as medidas revolucionárias que eram exigidas pela Regeneração. Retirando-se da política, activa aceitou em Junho de 1851 ser representante diplomático de Portugal em Londres.

9 "23 de Fevereiro de 1833 - O General La Fayette disse-me, em casa do Duque de Broglie, que tinha tido uma longa conversação com este sobre os negocios de Portugal, e que, dizendo-Ihe La Fayette: Voudriez-vous reconnaître don Miguel ? Broglie Ihe respondeu: Si nous reconnaissions don Miguel, nous ne ferions que suivre l'exemple des Etats-Unis. Eu disse ao General: On a voulu vous prendre par votre faible, maisj'espère que vous avez reconnu la ruse.

Não pode hoje haver duvida de que o Governo francez está pouco disposto a favor da Causa da Rainha.", Portugal, Francisco de Almeida, Memórias do Conde do Lavradio..., Coimbra, Imprensa da Universidade, 1932, Vol. II, p. 371. 
A intensidade da sua vivência política em Portugal explica a ausência, nas Memórias, de indicações específicas do seu pensamento sobre os Estados Unidos da América.

\section{A demagogia dos Estados Unidos}

A missão na Inglaterra era complexa e abrangia, entre outras, o tratamento das reclamações inglesas quanto à interpretação do Tratado de Comércio de 1842, a questão do Ambriz e os problemas com os Estados Unidos, a propósito do navio americano General Armstrong ${ }^{10}$. As responsabilidades inerentes à abordagem destas questões sensíveis da política externa nacional não o impedem de seguir com interesse o desenrolar dos acontecimentos internacionais no que respeita ao expansionismo norte-americano ${ }^{11}$. A consciência plena da estratégia dos Estados Unidos em direcção a uma provável anexação de Cuba esquecia apenas ou desconhecia que estas iniciativas não eram patrocinadas oficial ou oficiosamente pelo governo federal. Eram, sim, acções autónomas dos estados esclavagistas do sul dos EUA, empenhados na expansão do modo de produção colonial rumo às áreas tropicais da América Latina. Na verdade, a anexação de Cuba pelos americanos só se verificará nos anos 90 do século XIX, mas numa conjuntura política muito diferente. As possibilidades de se materializarem estas perspectivas parecem ser remotas, devido à oposição moderada da Inglaterra' ${ }^{12}$.

10 "27 de Agosto de 1851. - Hoje, pelas oito horas e meia da tarde, vieram a minha casa os Ministros do Reino e dos Negocios Extrangeiros, e, depois de passarem em revista as differentes reclamações inglezas, resolveram que eu seria encarregado de tratar em Londres as que eram relativas á interpretação do Tratado de Commercio de 1842, e outrosim a respeito do Ambriz. Egualmente resolveram que seria conveniente que eu entreviesse na questão que existe entre Portugal e os Estados Unidos, de que é arbitro o Presidente da Republica Franceza, a respeito do navio General Armstrong, e que se me desse uma inspecção sobre as Legações de Paris, de Bruxellas e d'outras; e, finalmente, que a questão do Ambriz se devia ligar com a da abolição da escravatura nas nossas possessões.", Portugal, Francisco de Almeida, Memórias do Conde do Lavradio..., Coimbra, Imprensa da Universidade, 1937, Vol. IV, p. 17. Ver Magalhães, José de Calvet, História das Relações Diplomáticas entre Portugal e os Estados Unidos da América (1776-1911), Lisboa, Publicações Europa-América, 1991, pp. 145-169.

11 "16 de Setembro de 1851 - (...) A nova tentativa de expedição americana, commandada pelo aventureiro Lopez contra a ilha de Cuba, tem aqui feito grande sensação, e parece indubitavel que o Governo dos Estados-Unidos não tem sido extranho ás duas tentativas que, para felicidade da Hespanha, fôram mallogradas. Parece-me, porem, que a guerra entre a Hespanha e os Estados-Unidos será inevitavel, e que o seu resultado será vir a ilha de Cuba a pertencer á União Americana. Não creio que o Governo Inglez faça grandes esforços para sustentar os direitos da Corôa Hespanhola á conservação de Cuba.", Portugal, Francisco de Almeida, Memórias do Conde do Lavradio..., Coimbra, Imprensa da Universidade, 1937, Vol. IV, p. 27.

12 "26 de Setembro de 1851. - O Ministro de Hespanha, com quem estou em muito boas relações e que é homem de merecimento, disse-me que o Governo Inglez tinha expedido ordens positivas à Estação 
Apesar do cepticismo sobre uma possível intervenção inglesa, esta não deixava de ser provável face aos seus interesses na América Central e nas Caraíbas, que as acções dos aventureiros americanos punham em causa. Além da presença britânica na Jamaica, nas Honduras e na Guiana, o combate ao tráfico dos escravos pela Royal Navy, na América do Sul, seria completamente posto em causa pelo alargamento da área dos estados esclavagistas dos EUA. Assim sendo, compreende-se que o conde do Lavradio, preocupado com as negociações com a Inglaterra sobre as reclamações inglesas do Tratado de 1842, fosse também sensível aos problemas da América Latina em geral e, principalmente, do Brasil, onde mantinha as suas raízes. A boa amizade entre Portugal e o Brasil reforçava tais preocupações e justificava a sua oferta ao embaixador brasileiro para servir de intermediário entre a Corte do Rio de Janeiro e a Inglaterra no tocante à captura de navios brasileiros acusados de traficarem escravos. Aliás, considerava que, se o governo britânico não desse uma satisfação ao Brasil, este se lançaria nos braços dos Estados Unidos da América perdendo a Inglaterra toda a sua influência ${ }^{13}$.

A arbitragem pedida ao presidente da França (Luís Napoleão Bonaparte) na controvérsia entre Portugal e os EUA sobre o navio General Armstrong implicou o pedido de media-

Naval da Jamaica para, no caso de haver uma nova tentativa contra a ilha de Cuba, se unir á Esquadra franceza e impedirem de accordo qualquer nova agressão contra aquella ilha.

Acrescentou que tambem sabia que tinham sido mandadas instrucções ao Ministro de Inglaterra nos Estados Unidos para protestar contra qualquer protecção directa ou indirecta que aquellle Governo desse a novos aventureiros que tentassem revoltar a sobredita ilha contra o dominio hespanhol. Apesar de tudo isto, não creio (e tal é também a opinião de Istúriz) que este Governo tome grande calor a favor da Hespanha, se acaso entre o Governo de Sua Majestade Catholica e o dos EstadosUnidos se suscitarem difficuldades, das quaes possam resultar hostilidades entre estes dois ultimos Governos. (...)", Portugal, Francisco de Almeida, Memórias do Conde do Lavradio..., Coimbra, Imprensa da Universidade, 1937, Vol. IV, p. 28. Consultar Jones, Maldwin A., The Limits of Liberty. American History 1607-1992, Oxford/New York, Oxford University Press, 1995, pp. 196-218.

13 "Os jornaes francezes e inglezes dão noticia dos graves insultos feitos á bandeira imperial do Brasil pelas forças navaes inglezas, sob o falso pretexto de se evitar o trafico. A indignação do Governo e subditos brasileiros contra esta inqualificavel conducta tem sido grande, e muito maior será quando alli chegar a noticia de que o Governo Britanico não só se não presta a dar uma cabal satisfação dos atentados commettidos pela sua Marinha, mas, pelo contrario, pretende sustentar a sua justiça.

A conducta do Governo Britanico, nestas circumstancias, é não só injusta e contraria á opinião publica em Inglaterra, especialmente nos portos que mais relações commerciaes teem com o Brasil, taes como Liverpool, etc. Julgo que, se o Governo Britanico não der uma conveniente satisfação ao Brasil, este, apesar dos perigos que corre, se lançará nos braços dos Estados-Unidos, e a Inglaterra perderá para sempre a sua influencia, tanto politica como commercial, no Brasil.", Portugal, Francisco de Almeida, Memórias do Conde do Lavradio..., Coimbra, Imprensa da Universidade, 1937, Vol. IV, p. 32. 
ção inglesa junto das autoridades francesas para uma resolução favorável ao nosso país ${ }^{14}$, o que efectivamente se verificou ${ }^{15}$.

14 "21 de Outubro de 1851. - Tendo chegado a Londres o Conde da Azinhaga, Ministro de Portugal em Paris, e tendo-me manifestado o desejo de ser apresentado a Lord Palmerston, fui hoje fazer essa apresentação. O Conde foi recebido com a attenção que lhe era devida, e aproveitou a occasião para pedir a Lord Palmerston que escrevesse ao Embaixador de Inglaterra junto do Governo da Republica Franceza, recomendando-lhe que apoiasse com energia as justas pretensões do Governo Portuguez, a respeito das reclamações do Governo dos Estados Unidos, que, por commum accordo dos dois Governos, fôram submettidas ao julgamento, como arbitro, do Presidente da Republica Franceza.

$\mathrm{Eu}$, a rogo do Conde da Azinhaga, não só juntei as minhas ás suas instancias, mas observei a Palmerston que o Governo Britanico tinha o rigoroso dever de sustentar as justas pretensões do Governo de Sua Majestade, o que eu me compromettia a provar, se fôsse necessario.

Palmerston fez algumas observações sobre a minha asserção, promettendo, comtudo, escrever ao Marquez de Normanby, fazendo-lhe as recomendações que eu e o Conde da Azinhaga desejavamos. Declarou ignorar que o Presidente da Republica Franceza tivesse sido nomeado arbitro para a decisão d'esta questão, acrescentando logo que a escolha de tal arbitrio tinha sido muito bôa e mostrando-me a sua sympathia pelo actual Presidente da Republica Franceza.", Portugal, Francisco de Almeida, Memórias do Conde do Lavradio..., Coimbra, Imprensa da Universidade, 1937, Vol. IV, p. 37. Consultar Agulhon, Maurice, «1848 ou l'aprentissage de la république 1848-1852», Nouvelle histoire de la France contemporaine, Vol. VIII Paris, Éditions du Seuil, 1973, pp. 140-164. E também Magalhães, José de Calvet, História das Relações Diplomáticas entre Portugal e os Estados Unidos da América (1776-1911), Lisboa, Publicações Europa-América, 1991, pp. 145-169.

15 "16 de Dezembro de 1852. - (...) Chegou hoje a Londres o Secretario da Legação de Portugal em Paris, sendo portador da sentença arbitral proferida pelo Chefe da Nação Franceza, sobre a pendencia que existia entre o Governo Portuguez e o dos Estados Unidos. A sentença é conforme aos justos desejos de Portugal.

A noticia desta decisão causou-me grande satisfação, mas nenhuma surpresa: $1 .{ }^{\circ}$ porque a justiça de Portugal era evidente; $2 .^{\circ}$ porque em 29 do mez de Setembro ultimo, indo eu em companhia do Conde da Azinhaga visitar o Barão Brénier, este nos disse que era elle o relator do processo relativo ao navio Armstrong, que os Governos Portuguez e dos Estados Unidos haviam submettido á decisão arbitral do Presidente da Republica Franceza; que elle, depois de haver examinado os documentos, que lhe haviam sido apresentados por parte dos dois Governos, havia reconhecido a justiça do Governo Portuguez, e nesse sentido tinha redigido o seu relatorio (cujas conclusões nos communicou confidencialmente), o qual ia ser submettido a uma commissão nomeada pelo Presidente. Nesta occasião me disse Brénier que os documentos e esclarecimentos, de que se havia servido para o seu relatorio e sua favoravel conclusão, eram os que Ihe havia ministrado o Conde da Azinhaga, aproveitando esta occasião para fazer grandes elogios ao dito Conde, e para me dizer que sentiria muito que se confimasse o boato, que se havia espalhado, de que o Conde ia ser substituido. O Conde da Azinhaga cumpriu o seu dever com zêlo e intelligencia, e a decisão favoravel sobre a questão do Armstrong foi devida, em parte, aos seus esforços. A primeira recompensa d'estes foi a sua demissão, precedida d'uma notavel desattenção; egual recompensa devem esperar os outros servidores do Estado, que, só fiados na pureza da sua consciencia e na sua inteira dedicação ao serviço, não curam de evitar sordidas e traiçoeiras intrigas. Estas e outras considerações, se bem que augmentam o meu ardente desejo de obter a minha demissão, não afrouxarão por certo o meu zêlo no serviço. Oxalá eu possa prestar algum de grande valia, 
As desilusões com a carreira diplomática e o comportamento oportunista, mesquinho e vingativo da classe política nacional face aos servidores do Estado levam-no a comparar a sua situação com a dos plenipotenciários americanos. A comparação é elogiosa para o governo americano e profundamente negativa para os sucessivos ministérios portugueses que tratam de uma maneira desprezível os seus diplomatas ${ }^{16}$. Todavia, a fidelidade aos interesses nacionais não o deixa, apesar das dificuldades, desamparar a Legação de Londres no ano de 1853 vendo-se obrigado a defender a política da Regeneração e a abordar a questão do tráfico de escravos. A opinião de D. Francisco de Almeida era a de que os verdadeiros negreiros não eram os portugueses mas os americanos, o que confirma a má imagem que os europeus tinham dos EUA como Estado que permitia a escravatura17. Nesta perspectiva a república norte-americana estava, de certa maneira, à margem dos países mais civilizados da comunidade internacional da época.

O início da Guerra da Crimeia (1853-1856) estava iminente e, consequentemente, o cuidado com o respeito pelo direito dos neutros leva-o a interrogar, em 1854, o governo inglês sem obter uma posição clara, tanto mais que isto envolvia a maior parte das nações europeias e os Estados Unidos da América. O banquete com o Lord Mayor de Londres, oferecido ao corpo diplomático nesse mesmo ano, apenas parece confirmar as suas ideias da proximidade do conflito entre a Inglaterra, a França e a Rússia. O facto de o governo inglês tomar uma posição no caso dos neutros, relativamente aberta em atenção à próxima guerra, deve-se não tanto às suas pressões mas às do governo francês e, sobretudo, do americano cujo poder e influência são cada vez maiores e, na sua opinião, também sobre a Europa ${ }^{18}$. Uma profecia por parte de um observador arguto sobre o futuro dos EUA, que

embora as honras fiquem a outrem !", Portugal, Francisco de Almeida, Memórias do Conde do Lavradio..., Coimbra, Imprensa da Universidade, 1937, Vol. IV, pp. 183-184.

16 "8de Janeiro de 1853.-(...) O Morning-Post de hontem publica uma correspondencia dos Plenipotenciarios dos Estados Unidos com o seu Governo, relativa aos ordenados, de que estes empregados carecem nas differentes Côrtes.

O Ministro Americano em Londres emitte a opinião, fundada em bons calculos, de que o ordenado dos Ministros Plenipotenciarios em Londres não deveria ser inferior a vinte mil dollares, isto é, quatro mil libras esterlinas, posto que elle, apesar de proceder com economia e sem ostentação nas suas despesas, gaste anualmente mais do que a sobredita quantia. O Ministro de Portugal apenas recebe annualmente mil e duzentas libras, quando toda a despesa annual d'esta Legação somma duas mil trezentas e quarenta e cinco libras, isto é, quasi metade da quantia que o Ministro Americano julga absolutamente necessaria para a decente sustentação do Chefe de Missão.", Portugal, Francisco de Almeida, Memórias do Conde do Lavradio..., Coimbra, Imprensa da Universidade, 1937, Vol. IV, p. 203.

17 Cf.Portugal, Francisco de Almeida, Memórias do Conde do Lavradio..., Coimbra, Imprensa da Universidade, 1937, Vol. IV, p. 250.

${ }_{18}$ Cf.Portugal, Francisco de Almeida, Memórias do Conde do Lavradio..., Coimbra, Imprensa da Universidade, 1938, Vol. V, pp. 44-45. 
ainda demoraria muito tempo a verificar-se, mas que, sem dúvida, reflecte a consciência da importância presente e futura da grande república do outro lado do Atlântico ${ }^{19}$. O evoluir da Guerra da Crimeia na Europa mantém um clima de confrontos diplomáticos com os Estados Unidos, sendo o banquete do Lord Mayor uma ocasião especialmente crítica, propícia a provocar incidentes e provocações ${ }^{20}$ ! A república norte-americana era, assim, compreendida como uma entidade estranha ao universo das potências europeias e ao seu mundo político. O receio de uma provocação política e revolucionária do embaixador americano tem como contraposição a aliança dos representantes diplomáticos europeus em Londres para o boicotarem, o que aliás, conseguiram.

Os Estados Unidos da América do Norte são demasiado importantes para a indústria têxtil inglesa, por causa do fornecimento do algodão dos estados do Sul, para poderem perigar as relações entre os dois países e, portanto, existe um fechar de olhos do governo britânico ao tráfico de escravos para os EUA e da escravatura existente naquele país. A Guerra da Crimeia obriga a uma redução dos transportes para a América do Norte, mas não altera o entendimento dos dois lados do Atlântico Norte. O expansionismo dos Estados Unidos na América é considerado como uma estratégia de impacto directo no

${ }^{19} \mathrm{Cfr}$ Portugal, Francisco de Almeida, Memórias do Conde do Lavradio..., Coimbra, Imprensa da Universidade, 1938, Vol. V, p. 70.

20 "16 de Novembro de 1854. - (...) Lord Clarendon communicou estes sentimentos do Lord Maior ao Embaixador da França, a mim e a alguns outros mais dos meus collegas, mostrando-nos, sobretudo ao Embaixador da França, o desejo de retirarmos as nossas escusas e que aceitassemos o convite do Primeiro Magistrado da Cidade, por diversos motivos, mas até para impedir que a saude, que é de estilo fazer ao Corpo Diplomatico, fôsse agradecida pelo Ministro dos Estados Unidos, que, sem duvida, aproveitaria a occasião para fazer um imprudente discurso, que obrigaria a dar-lhe alguma desagradavel resposta, que podia ter consequencias, sobretudo estando ainda recente o procedimento do Governo Francez para com Mr. Saulé e sendo induvitavel que os Americanos desejam aproveitar toda a occasião que se Ihes offerece para suscitarem complicações com os Governos da Europa.

O Embaixador da França, como era de esperar, annuiu promptamente aos desejos manifestados por Clarendon, e instou comigo e com outros para que seguissemos o seu exemplo. Posto que reconhecesse que me seria incommodo e até prejudicial á saude assistir a um fastidioso banquete de mil e quinhentas pessoas, prestei-me de bom grado ao sacrificio que de mim se exigia, e o mesmo praticaram, alem do Embaixador da França, os seguintes Chefes de Missão: Ministros da Sardenha, Turquia, Brasil, Austria, Estados Unidos, Dinamarca, Hespanha, Suecia e Encarregado de Negocios do Peru. O Embaixador da França fallou em nome do todos, e o Ministro dos Estados Unidos foi obrigado a ficar silencioso, o que visivelmente o contrariou, porque ficou inhibido de fazer as provocações que provavelmente havia premeditado no seu Gabinete. (...) Segundo os calculos mais exactos, as manufacturas inglezas de algodão, se houvesse uma interrupção de communicações com os Estados Unidos, no fim de quatorze semanas não teriam mercado para os seus productos. Posto isto, não creio que a desintelligencia actual possa passar a uma guerra.". Portugal, Francisco de Almeida, Memórias do Conde do Lavradio..., Coimbra, Imprensa da Universidade, 1938, Vol. V, pp. 122-123. 
futuro da Europa. O conde do Lavradio tem uma curiosa capacidade de valorizar o futuro peso político de uma potência emergente, embora geograficamente fora do espaço político europeu, mas capaz de o condicionar. $O$ risco passa também pela difusão das ideias democráticas da república norte-americana, passíveis de subverter a ordem política de outra potência nas margens da Europa e no pólo ideológico oposto, mas ironicamente cúmplices ${ }^{21}$. Os Estados Unidos e a Rússia com sistemas políticos opostos cooperam activamente em defesa do direito dos neutros contra as interferências navais, sobretudo da Royal Navy. A convergência de interesses das duas torna evidente as resistências à imposição, por parte da Inglaterra, de um modelo rígido de aplicação dos direitos neutros durante a Guerra da Crimeia. Os Estados Unidos da América não estão distantes de certos Estados europeus no que diz respeito a certos "hábitos" políticos como, por exemplo, o patronato parlamentar inglês ${ }^{22}$. No entanto, o impacto ideológico da existência dos Estados Unidos da América é algo que parece preocupar franceses, ingleses e portugueses como nos refere no final da Guerra da Crimeia:

"3 de Outubro de 1855. - (...) O Embaixador replicou: A alliança há-de conservar-se, porque é da utilidade das duas Nações ameaçadas, como toda a Europa, por um lado pela Russia, e por outro pela demagogia dos Estados Unidos. Sobre este thema dissertou elle muito tempo. Lord Clarendon approvou a proposição, e eu apenas observei que não só havia a temer os Estados Unidos, mas tambem a demagogia da Europa, principalmente a da França." ${ }^{23}$

21 "6 de Dezembro de 1854. - (...) Emquanto a guerra atormenta a Europa, o Governo dos Estados Unidos, activamente coadjuvado pelos seus incançaveis e revolucionarios agentes, procura aproveitar-se das circumstancias para estender o seu domínio na America e influir nos futuros destinos da Europa. Alem do seu tratado ostensivo, ultimamente celebrado com a Russia, dizem que celebrou outro secreto com a mesma Potencia. A união d'estas duas Potencias, cujas organizações politicas são oppostas, é caso curioso, e talvez com o andar dos tempos terá graves consequencias para a Russia. Não há risco que os principios d'esta ultima Potencia sejam recebidos nos Estados Unidos, mas os d'estes podem achar sympathias na Russia.", Portugal, Francisco de Almeida, Memórias do Conde do Lavradio..., Coimbra, Imprensa da Universidade, 1938, Vol. V, p. 138. Consultar Perkins, Bradford, "The Creation of a Republican Empire, 1776-1865", Cohen, Warren I. Editor, The Cambridge History of American Foreign Relations, Cambridge, Cambridge University Press, 1995, vol. I, pp. 170-233.

22 "16 de Maio de 1855. - (...) Na Camara dos Communs teem as classes medias aberta a arena, para alli conquistarem os logares a que os seus talentos Ihes dão direito. Não negarei a existencia do patronato, mas este raras vezes deixa de ser exercido a favor de pessoas de merecimento. E qual é o Estado onde não existe o patronato? Eu não o defendo, antes o condemno, mas sustento que elle existe em todos os paizes, e que o paiz onde elle existe da maneira mais escandalosa é na democracia Republica dos Estados-Unidos da America do Norte.", Portugal, Francisco de Almeida, Memórias do Conde do Lavradio..., Coimbra, Imprensa da Universidade, 1938, Vol. V, p. 211.

${ }^{23}$ Cf.Portugal, Francisco de Almeida, Memórias do Conde do Lavradio..., Coimbra, Imprensa da Universidade, 1938, Vol. V, p. 249. 
O medo do contágio ideológico da "demagogia dos Estados Unidos" não impede que a Inglaterra e a república americana tenham interesses económicos comuns que os obrigam a conviver apesar das diferenças políticas ${ }^{24}$.

\section{O expansionismo americano}

A questão do reconhecimento dos direitos portugueses sobre a região africana do Ambriz origina não só novos problemas com Portugal, mas também com os Estados Unidos da América ${ }^{25}$. O princípio do ano de 1856 é marcado pelo reacender do conflito diplomático anglo-luso sobre os direitos da coroa portuguesa ao porto de Ambriz, a ocupação por Portugal e o tráfico de escravos. As tentativas inglesas destinadas a impedir a ocupação nacional do Ambriz resultam, em sua opinião, do desejo de estabelecer um protectorado na região, como o fizeram na Costa da Mina. Assim sendo, afastariam o comércio nacional em proveito do inglês com a desculpa de desconfiarem que os portugueses se dedicavam ao tráfico dos escravos. A melhor maneira de contrabater as pressões é recorrer à França e aos EUA, jogando com as suas rivalidades com os britânicos e a supressão da escravidão na área ${ }^{26}$. Todavia, os problemas entre a Grã-Bretanha e os Estados Unidos são um tema recorrente e paralelo à questão do Ambriz. O risco de uma guerra entre aqueles dois países sobre disputas não resolvidas está sempre presente no horizonte, ainda que D. Francisco de Almeida não acredite que venha a acontecer devido à disparidade das forças das duas armadas ${ }^{27}$. Em presença das pressões constantes dos ingleses pode jogar a cartada de um acordo com os americanos sobre o Ambriz, o que

24 "6 de Novembro de 1855. - (....) Tem ultimamente havido desintelligencias entre este Governo e o dos Estados Unidos. Este ultimo tem sido movido, não só pelo constante desejo que tem de inquietar a Inglaterra, como tambem pelas instigações da Russia. São comtudo, tão grandes os interesses commerciaes que existem entre a Inglaterra e os Estados Unidos, que estes dois paizes carecem um do outro.", Portugal, Francisco de Almeida, Memórias do Conde do Lavradio..., Coimbra, Imprensa da Universidade, 1938, Vol. V, p. 282.

25 "10 de Dezembro de 1855. - (...) Referi-Ihe tambem, muito confidencialmente, o que se havia passado em Lisboa entre o Ministro dos Estados Unidos e o Visconde de Athouguia, e que Buchanan me havia procurado para me fallar no negocio do Ambriz. A esta minha communicação não respondeu Lord Clarendon uma só palavra.", Portugal, Francisco de Almeida, Memórias do Conde do Lavradio..., Coimbra, Imprensa da Universidade, 1938, Vol. V, p. 309.

${ }^{26}$ Cf.Portugal, Francisco de Almeida, Memórias do Conde do Lavradio..., Coimbra, Imprensa da Universidade, 1940, Vol. VI, p. 21.

${ }_{27}$ Cf.Portugal, Francisco de Almeida, Memórias do Conde do Lavradio..., Coimbra, Imprensa da Universidade, 1940, Vol. VI, p. 26. 
demonstra o peso crescente dos EUA e a consciência que o diplomata português tem da sua importância no contexto internacional ${ }^{28}$.

A sua estratégia perante o problema do Ambriz merece, sintomaticamente, o apoio do visconde de Sá da Bandeira, pois as rivalidades entre a Inglaterra e os EUA na América Central criam um mal-estar entre os dois países que pode ser aproveitado a favor de Portugal ${ }^{29}$. Deste ponto de vista seria útil obter o apoio dos Estados Unidos prometendo- Ihes e fazendo-Ihes algumas concessões, em troca do reconhecimento formal dos direitos da coroa portuguesa na costa de África. Considera os EUA nos anos 50 do século XIX uma potência emergente e suficientemente importante para ser usada como contrapeso regional dos ingleses. A sua importância em África é de tal modo relevante que propõe que, em última instância, Ihe seja mesmo concedida a livre navegação do rio Zaire ${ }^{30}$. O final da Guerra da Crimeia não alterará a situação, mantendo-se o conflito entre a Inglaterra e os Estados Unidos no caso específico da América Central ${ }^{31}$. Os incidentes entre os dois países cresceram com a expedição do aventureiro americano Walker à Nicarágua. A ruptura das relações diplomáticas parece iminente, como o atesta o desagrado americano face a Crompton, representante britânico em Washington. No entanto, a força naval inglesa é de tal forma superior à americana que os desacertos não chegam a esse ponto crítico ${ }^{32}$. As concessões inglesas aos americanos, a propósito da interpretação do Tratado anglo-americano de 1850, comprovam os esforços do governo britânico para apaziguar os EUA e evitar a escalada do conflito na América Central entre os dois países ${ }^{33}$.

\section{A Guerra da Secessão (1861-1865)}

Os anos que decorrem entre o final da Guerra da Crimeia (1856) e o início da Guerra da Secessão americana (1861) foram sobretudo marcados pelas preocupações portu-

${ }^{28}$ Cf. Portugal, Francisco de Almeida, Memórias do Conde do Lavradio..., Coimbra, Imprensa da Universidade, 1940, Vol. VI, pp. 59-60.

${ }^{29}$ Cf.Portugal, Francisco de Almeida, Memórias do Conde do Lavradio..., Coimbra, Imprensa da Universidade, 1940, Vol. VI, pp. 66-67.

${ }^{30}$ Cf.Portugal, Francisco de Almeida, Memórias do Conde do Lavradio..., Coimbra, Imprensa da Universidade, 1940, Vol. VI, pp. 67-68.

${ }^{31}$ Cf.Portugal, Francisco de Almeida, Memórias do Conde do Lavradio..., Coimbra, Imprensa da Universidade, 1940, Vol. Vl, p. 73.

32 Cf.Portugal, Francisco de Almeida, Memórias do Conde do Lavradio...,Coimbra, Imprensa da Universidade, 1940, Vol. VI, p. 87.

33 Portugal, Francisco de Almeida, Memórias do Conde do Lavradio..., Coimbra, Imprensa da Universidade, 1940, Vol. VI, p. 101. 
guesas com a eleição do novo presidente americano James Buchanan (1856-1860) e as explorações do escocês Livingston em África. As ameaças à integridade das colónias portuguesas de Angola e de Moçambique pressentidas pelas actividades científicas e filantrópicas de Livingston não deixavam muito tempo para uma reflexão sobre a evolução da política interna dos EUA. No entanto, o novo presidente era considerado como um defensor dos esclavagistas e estava, aparentemente, interessado na expansão do comércio dos escravos com África. Buchanan e Livingston representavam a acção expansionista de duas potências capazes de pôr em causa as colónias nacionais. Assim sendo, o diplomata português não se apercebeu, de imediato, do conflito iminente entre os estados do Norte e do Sul da república americana. Um dos primeiros sintomas da gravidade da situação interna dos Estados Unidos da América do Norte surge em 16 de Abril de 1861 pela mão de um dos industriais de têxteis de Manchester, preocupado com a provável falta do algodão que vinha principalmente dos estados confederados, em busca de fontes alternativas quer no Brasil quer na África portuguesa. Daí as reflexões sobre a questão, a propósito da entrevista com Mr. Bazley, deputado e fabricante de Manchester, interessado em que Portugal desenvolvesse a produção de algodão nas suas colónias ${ }^{34}$. Em breve a guerra civil tem implicações internacionais nomeadamente na beligerância entre os neutros que atinge também Portugal e é objecto de uma conversa em Londres com Lord John Russel sobre o estatuto dos confederados como beligerantes ${ }^{35}$.

A situação referente à Guerra da Secessão americana ganha novos contornos com a iminente partida de uma expedição espanhola contra o México para obter uma reparação diplomática e o pagamento de dívidas. Esta iniciativa é considerada absurda e uma provocação aos Estados Unidos que, uma vez acabada a guerra civil, se podem vingar ocupando Cuba e Porto Rico em vez de procurarem recuperar, em vão, as antigas províncias perdidas $^{36}$. O evoluir do conflito, entre unionistas e confederados, provoca um conflito diplomático entre o governo britânico e Washigton a respeito da captura dos diplomatas confederados, que viajavam no navio inglês Trent, pela fragata San Hyacinth ao serviço da União. A previsão pessimista é a da declaração de guerra, a breve prazo, entre os dois Estados e,

${ }^{34}$ Cf. Portugal, Francisco de Almeida, Memórias do Conde do Lavradio..., Coimbra, Imprensa da Universidade, 1943, Vol. VIII, p. 44. Ver McPherson, James M., Battle Cry of Freedom The American Civil War, London/ New York, Penguin Books, 1990, pp. 369-568.

${ }^{35}$ Cf.Portugal, Francisco de Almeida, Memórias do Conde do Lavradio..., Coimbra, Imprensa da Universidade, 1943, Vol. VIII, pp. 49-50.

${ }^{36}$ Cf.Portugal, Francisco de Almeida, Memórias do Conde do Lavradio..., Coimbra, Imprensa da Universidade, 1943, Vol. VIII, pp. 75-76. 
provavelmente, o apoio naval inglês aos confederados ${ }^{37}$. O mais importante são as reflexões sobre a realidade política dos Estados Unidos contraposta idealisticamente, desde o livro de Alexis de Tocqueville sobre a democracia americana, à evolução europeia. Ou seja, a preocupação de D. Francisco de Almeida é valorizar o insucesso daquela república apresentada sempre como o modelo de progresso social e político democrático:

"6 de Dezembro de 1861. - (...) Os acontecimentos dos Estados Unidos durante estes ultimo anno, sendo bem estudados, offerecem uma boa lição aos Governos e aos Povos. Está hoje bem demonstrado que a prosperidade d'aquelles Estados, que a todos assombrava, era devida á sua riqueza natural, mas de modo algum á sua monstruosa e desmoralizadora organização social. Que confiança pode haver numa forma de governo baseada sobre revoluções legaes, preparadas por uma descarada corrupção e onde a responsabilidade dos agentes do Governo é uma completa ficção ? Desde que desappareceram os caracteres respeitaveis, que de boa fé fundaram os Estados Unidos, o Governo cahiu nas mãos de intrigantes, elevados ao poder pela corrupção e pelas paixões das turbas excitadas pelos immoraes follicularios, que se locupletavam e subiam ao poder por meio da calumnia e das violencias que haviam excitado.

Antes de concluido um seculo, deixou de existir a decantada união, e, se a guerra com a Inglaterra tiver logar, a Inglaterra, se isso Ihe conviesse, que não Ihe convem, poderia reconquistar os seus antigos dominios.

Seja como for, os Estados Unidos, em consequencia da sua má organização, perderão num anno o seu prestigio, que só poderão reganhar reformando as suas instituições.

Vive ainda hoje em Londres uma grande notabilidade, com quem tenho tido boas relações Lord Lynhurst, que nasceu em Boston, quando esta cidade era colonia ingleza, viu a revolução, presenciou o reconhecimento da independencia dos Estados Unidos, e hoje, conservando ainda clarissima a sua grande intelligencia e com forças sufficientes, não só para assistir, mas para tomar parte conspicua nas discussões das mais importantes questões que se tratam no Parlamento, está presenceando a separação d'essa que se julgava indispensavel união.

Poderá porventura admirar-se a sabedoria de instituições que não chegam a poder durar a vida de um homem? Comparem-se as instituições dos Estados Unidos com as inglezas, e então se conhecerá a excellencia d'estas e a imperfeição d'aquellas.

De Lisboa recebi a carta credencial para eu continuar exercendo as funcções de Ministro Plenipotenciario em Londres." ${ }^{\prime 38}$

${ }^{37}$ Cf. Portugal, Francisco de Almeida, Memórias do Conde do Lavradio..., Coimbra, Imprensa da Universidade, 1943, Vol. VIII, pp. 88-89. Ver McPherson, James M., Battle Cry of Freedom The American Civil War, London/ New York, Penguin Books, 1990, pp. 369-568.

${ }^{38}$ Cf.Portugal, Francisco de Almeida, Memórias do Conde do Lavradio..., Coimbra, Imprensa da Universidade, 1943, Vol. VIII, pp. 89-90. 
Assim sendo, a questão da declaração ou não da guerra entre ingleses e americanos é mais um teste à viabilidade da grande república americana, cuja simples existência põe em causa a perenidade das monarquias europeias mesmo liberais ${ }^{39}$. O pessimismo sobre a evolução do conflito anglo-americano dá lugar a uma visão mais optimista no referente ao caso Trent, a propósito da moderação dos governos dos dois países ${ }^{40}$. 0 caso do Trent permite-Ihe retomar uma série de temas recorrentes sobre os Estados Unidos da América, a Inglaterra e as colónias africanas e colocar a questão da posição de Portugal frente aos beligerantes da guerra civil entre nortistas e sulistas ${ }^{41}$. A neutralidade portuguesa é algo essencial para Portugal e para a Inglaterra, embora exista um compromisso de Palmerston de não esquecer as obrigações face a Portugal, em caso de conflito entre ingleses e americanos. $\mathrm{O}$ anúncio de que os americanos tinham entregado os prisioneiros confederados do Trent parece indicar uma melhoria das relações entre americanos e ingleses e afastar a perspectiva de confronto militar violento que, segundo D. Francisco de Almeida, teria consequências trágicas para a causa da União, abrindo caminho ao reconhecimento internacional da Confederação e à sua vitória final. A amplitude internacional tomada por este caso conduziu a uma reflexão mais vasta sobre a diplomacia inglesa e a inevitabilidade da guerra anglo-americana, pois o conflito está apenas apaziguado por agora. O problema que se coloca é o de uma melhor definição do direito dos neutros, para o qual procura mobilizar os outros diplomatas residentes em Londres ${ }^{42}$. A resposta inglesa a esta proposta é totalmente negativa porque deseja proteger a Confederação do Sul que sairia fortemente prejudicada se estes direitos dos neutros fossem fixados ${ }^{43}$.

A guerra civil aparenta continuar indecisa parecendo só existir uma solução através da mediação entre o Norte e o Sul. No futuro tudo se pode complicar devido à expedição anglo-franco-espanhola ao México ${ }^{44}$. A questão vai ganhando importância devido à

${ }^{39}$ Cf. Portugal, Francisco de Almeida, Memórias do Conde do Lavradio..., Coimbra, Imprensa da Universidade, 1943, Vol. VIII, p. 91. Ver McPherson, James M., Battle Cry of Freedom The American Civil War, London/New York, Penguin Books, 1990, pp. 369-568.

${ }^{40}$ Cf.Portugal, Francisco de Almeida, Memórias do Conde do Lavradio..., Coimbra, Imprensa da Universidade, 1943, Vol. VIII, pp. 92-93. Ver McPherson, James M., Battle Cry of Freedom The American Civil War, London/ New York, Penguin Books, 1990, pp. 369-568.

${ }^{41}$ Cf. Portugal, Francisco de Almeida, Memórias do Conde do Lavradio..., Coimbra, Imprensa da Universidade, 1943, Vol. VIII, pp. 101-102.

${ }^{42}$ Cf.Portugal, Francisco de Almeida, Memórias do Conde do Lavradio..., Coimbra, Imprensa da Universidade, 1943, Vol. VIII, pp. 104-105.

${ }^{43}$ Cf. Portugal, Francisco de Almeida, Memórias do Conde do Lavradio..., Coimbra, Imprensa da Universidade, 1943, Vol. VIII, p. 105.

44 "26 de Maio de 1862. - (...) Na questão do Mexico os Governos Inglez e Hespanhol estão de perfeito accordo, mas nem um nem outros pretendem obstar a que o Governo Francez prosiga na execução do 
intransigência francesa que deseja constituir um improvável império no México com o arquiduque austríaco Maximiliano como soberano ${ }^{45}$. A questão da Guerra da Secessão dos EUA (1861-1865) continua a dominar os seus pensamentos nomeadamente devido ao facto de lhe parecer iminente o reconhecimento por Londres e Paris da independência da Confederação. O apoio popular a esta decisão parece ser dominante na Grã-Bretanha, mas Gladstone avança com extrema precaução neste campo para evitar a guerra ${ }^{46}$. Estas

seu projecto de restaurar o Imperio do Mexico, tendo por chefe o Archiduque Maximiliano. A Inglaterra estimará, no interesse do seu commercio, que o Mexico se possa organizar á custa do ouro e do sangue francezes. Nesta questão, como em quasi todas, a Inglaterra tem tudo a ganhar e nada a perder.

A questão dos Estados Unidos continua indecisa, mas aqui todos os homens de Estado pensam que ella só poderá terminar por uma transacção entre o Norte e o Sul.", Portugal, Francisco de Almeida, Memórias do Conde do Lavradio..., Coimbra, Imprensa da Universidade, 1943, Vol. VIII, p. 130. Ver McPherson, James M., Battle Cry of Freedom The American Civil War, London/New York, Penguin Books, 1990, pp. 369-568.

45 "26 de Junho de 1862. - Sobre a questão do Mexico, apesar de os Governos Inglez e Hespanhol se haverem separado da França, parece-me que d'esta separação não resultará inconveniente grave para a alliança existente entre estes tres Governos. A França quer ir mais longe que as duas outras Nações, e estas não quizeram ultrapassar os fins da expedição nem os limites da Convenção, e creio que procederam com sabedoria e, sem duvida, com lealdade para com a França, o que o Governo Imperial reconhece, apesar de alguns imprudentes e infundados artigos de jornaes. O Governo Inglez, porem, não pretende tolher a acção da França no Mexico, e mesmo folgará que ella tenha um bom resultado, eu, sendo glorioso para a França, será proveitosos para o commercio britanio.

A questão da conveniencia de a Inglaterra e a França offerecerem a sua mediação aos Federados e Confederados da America já tem sido agitada não só nos jornaes, mas tambem no Parlamento. Os dois Governos, reconhecem ambos a conveniencia de terminar aquella guerra fratricida por meio de uma mediação. O Governo Francez, mais impaciente do que o Inglez, inclina-se a pensar que é já occasião de offerecer aquella mediação. Pelo contrario, o Governo Britanico, e muito particularmente Lord Palmerston, julga que a questão ainda não está madura, nem em Inglaterra, nem nos Estados Unidos. Mr. Rouher, um dos membros mais importantes do Gabinete Francez, pela sua grande capacidade, acha-se presentemente em Londres, encarregado pelo Imperador de discutir officiosamente esta importante questão." Portugal, Francisco de Almeida, Memórias do Conde do Lavradio..., Coimbra, Imprensa da Universidade, 1943, Vol. VIII, pp. 142-143.

46 "16 de Outubro de 1862. - (...) As palavras que Gladstone pronunciou num discurso em New-Castle indicam a disposição favoravel do Governo Britanico de reconhecer a independencia do Sul na guerra entre os Federados e Confederados dos Estados Unidos da America; comtudo, o Governo Britanico, apesar da sua grande força, superior hoje ás de todas as outras Nações do mundo, deseja proceder com a maxima prudencia, para evitar a possibilidade de uma guerra. É certo que entre os Gabinetes de Londres e de Paris se discute, posto que mui cautelosamente, quando e como se deverá reconhecer a independencia da Confederação do Sul. O publico insiste cada vez mais na necessidade d'este reconhecimento, o Governo deseja-o, mas quere fazê-lo com segurança. Esta é hoje uma das questões mais importantes que o Governo Britanico tem de resolver. Esta questão pode ser considerada como questão interna e externa." Portugal, Francisco de Almeida, Memórias do Conde do Lavradio..., Coimbra, Imprensa da Universidade, 1943, Vol. VIII, p. 161. Ver McPherson, James M., Battle Cry of Freedom The American Civil War, London/New York, Penguin Books, 1990, pp. 369-568. 
observações conduzem-nos ao final das memórias que, como nos refere o seu comentador, o marquês do Lavradio, são relativamente pobres em resultado da sua vida política posterior a 1865, marcada pela passagem de novo pela Câmara dos Pares no lugar de presidente, e, posteriormente, por ter assumido a embaixada de Roma de 1869 até à sua morte, em $1870^{47}$. Não será assim surpreendente que a última referência que encontramos nas Memórias do conde do Lavradio à Guerra da Secessão americana seja para comentar horrorizado o assassínio do presidente Abraham Lincoln (1860-1865), condenado por toda a Europa:

"4 de Maio de 1865. - A noticia do horrivel crime de que foi victima o Presidente Lincoln produziu em toda a Europa, mas particularmente em Inglaterra, uma forte e profunda indignação."148

O fim trágico da Guerra da Secessão americana coincide com o final anunciado da carreira diplomática do conde do Lavradio, embora esta só termine efectivamente com a sua morte em 1870! Todavia, ao longo dos anos, a sua visão dos Estados Unidos acompanhou as diversas vicissitudes internacionais da política externa norte-americana e portuguesa. O facto de ter tido uma vivência sul-americana brasileira nos seus anos de formação não o preparou para uma abertura de espírito face à nova realidade transatlântica da república norte-americana. No entanto, D. Francisco de Almeida foi um observador atento que detectou a crescente importância, não só regional mas progressivamente mundial, no presente e no futuro dos EUA. Os arcaísmo sociais resultantes da preservação da escravatura no sul deste país cruzavam-se com a extrema modernidade política de uma experiência democrática totalmente inédita para a Europa da época. Daí o receio e a perplexidade face a um expansionismo americano, considerado muitas vezes subversivo e perigoso pelos seus ideais, para os governos estabelecidos quer na América quer mesmo na Europa. O modelo político do conde do Lavradio era a monarquia parlamentar inglesa, considerada segundo a tradição clássica um regime misto composto pela monarquia, aristocracia e democracia, equilibrando-se num jogo de forças já explicado por Blackstone e Montesquieu. Assim sendo, os EUA eram de certo modo uma perigosa heresia política que punha em causa estes princípios e a sua visão do mundo. A "alegria" relativa com que assiste ao desencadear da guerra civil nos EUA resulta de parecer confirmar as suas ideias

${ }^{47}$ Cf. Marquês de Lavradio, Portugal, Francisco de Almeida, Memórias do Conde do Lavradio..., Coimbra, Imprensa da Universidade, 1943, Vol. VIII, p. 249.

${ }^{48}$ Cf. Portugal, Francisco de Almeida, Memórias do Conde do Lavradio..., Coimbra, Imprensa da Universidade, 1943, Vol. VIII, p. 260. 
da impossibilidade da sobrevivência de uma grande república democrática e sobretudo federal! A aparente desintregração da república americana parece-lhe valorizar o princípio da unidade política, presente em todas as constituições monárquicas e impossível de replicar num presidente eleito. A desconfiança sobre as eleições americanas, consideradas corruptas, leva-o a ser muito céptico sobre a viabilidade das suas instituições. Finalmente considera que, em parte pelo menos, os estados do Sul têm direito de se separar da união e criar uma confederação independente, apoiada por franceses e ingleses. $\mathrm{O}$ facto de a realidade histórica não ter confirmado as suas previsões apenas demonstra que D. Francisco de Almeida era um homem do seu tempo que olhava para os EUA como um "corpo estelar" estranho ao bem ordenado e hierarquizado "sistema solar" das potências do século XIX. 